Article

\title{
Effect of Electrode Configuration on Nitric Oxide Gas Sensor Behavior
}

\section{Ling Cui ${ }^{\dagger}$ and Erica P. Murray ${ }^{\dagger} * *$}

Institute for Micromanufacturing, Louisiana Tech University, Ruston, LA 71272, USA;

E-Mail: 1cu003@latech.edu

$\dagger$ These authors contributed equally to this work.

* Author to whom correspondence should be addressed; E-Mail: emurray @ latech.edu; Tel.: +1-318-257-5148; Fax: +1-318-257-5104.

Academic Editor: W. Rudolf Seitz

Received: 30 June 2015 / Accepted: 16 September 2015 / Published: 23 September 2015

\begin{abstract}
The influence of electrode configuration on the impedancemetric response of nitric oxide (NO) gas sensors was investigated for solid electrochemical cells [Au/yttria-stabilized zirconia (YSZ)/Au)]. Fabrication of the sensors was carried out at $1050{ }^{\circ} \mathrm{C}$ in order to establish a porous YSZ electrolyte that enabled gas diffusion. Two electrode configurations were studied where Au wire electrodes were either embedded within or wrapped around the YSZ electrolyte. The electrical response of the sensors was collected via impedance spectroscopy under various operating conditions where gas concentrations ranged from 0 to $100 \mathrm{ppm} \mathrm{NO}$ and $1 \%-18 \% \mathrm{O}_{2}$ at temperatures varying from 600 to $700{ }^{\circ} \mathrm{C}$. Gas diffusion appeared to be a rate-limiting mechanism in sensors where the electrode configuration resulted in longer diffusion pathways. The temperature dependence of the NO sensors studied was independent of the electrode configuration. Analysis of the impedance data, along with equivalent circuit modeling indicated the electrode configuration of the sensor effected gas and ionic transport pathways, capacitance behavior, and NO sensitivity.
\end{abstract}

Keywords: $\mathrm{NO}_{\mathrm{x}}$ sensors; diesel emissions; electrode configuration; porous YSZ electrolytes; impedance spectroscopy 


\section{Introduction}

Advancements in diesel fuel and engine technology continue to provide greater fuel efficiency and lower $\mathrm{NO}_{x}$ (i.e., $\mathrm{NO}$ and $\mathrm{NO}_{2}$ ) emissions for diesel powered vehicles. $\mathrm{NO}_{\mathrm{x}}$ emissions, which result from incomplete combustion of diesel fuel, are highly regulated by the US Environmental Protection Agency (EPA) as studies have shown that even concentrations as low as $20 \mathrm{ppm}$ can be harmful to the environment and human health [1,2]. To address this issue, various diesel aftertreatment systems including, lean $\mathrm{NO}_{\mathrm{x}}$ traps, selective catalytic reduction, fuel regeneration and diesel exhaust fluid (i.e., urea), have been implemented to reduce $\mathrm{NO}_{\mathrm{x}}$ to non-toxic gases [3,4]. $\mathrm{NO}_{\mathrm{x}}$ sensors are crucial for verifying that such aftertreatment systems are working effectively. Current $\mathrm{NO}_{\mathrm{x}}$ sensors are able to detect $\mathrm{NO}_{\mathrm{x}}$ at concentrations down to approximately $10 \mathrm{ppm}$. However, it is expected that the lower emissions resulting from further development in diesel engine technology, as well as increasingly stringent EPA standards, will require sensors that are capable of monitoring $\mathrm{NO}_{\mathrm{x}}$ concentrations as low as $1 \mathrm{ppm}$.

Yttria-stablized ziriconia (YSZ) has been widely used in $\mathrm{NO}_{\mathrm{x}}$ sensors as the solid-state electrolyte has a high tolerance for the harsh exhaust gas environment [5]. The electrolyte is typically accompanied with noble metal (or metal oxide) electrodes; and, $\mathrm{NO}_{\mathrm{x}}$ sensing is understood to take place at the electrolyte/electrode interface. Porous YSZ electrolytes have recently be shown to promote greater $\mathrm{NO}_{\mathrm{x}}$ sensitivity [6]. Studies have shown that the $\mathrm{NO}_{\mathrm{x}}$ sensor response is also dependent upon various properties related to the sensing electrode. For example, the material composition, microstructure, surface area, and geometry of the sensing electrode can affect the sensitivity, selectivity and response time of the $\mathrm{NO}_{\mathrm{x}}$ sensor [7-12]. Fewer studies have considered the role of electrode configuration on $\mathrm{NO}_{\mathrm{x}}$ sensing behavior. Interestingly, this aspect of the sensing electrode design directly impacts the electrochemical response and reliability of the $\mathrm{NO}_{\mathrm{x}}$ sensor [13]. Further knowledge of the role of the sensing electrode configuration can contribute to a more complete understanding of the electrode properties on gas sensing.

Although $\mathrm{NO}$ and $\mathrm{NO}_{2}$ are present in the diesel exhaust stream, $\mathrm{NO}$ tends to be more stable at elevated temperatures and is significantly more abundant (e.g., over $90 \%$ at $600{ }^{\circ} \mathrm{C}$ ) due to thermodynamic conversion of $\mathrm{NO}_{2}$. Hence, this study concentrates on the impedancemetric response to $\mathrm{NO}$ of porous YSZ electrolyte sensors with different electrode configurations. The influence of electrode configuration on gas and ionic transport pathways, reactions at the electrode/electrolyte interface, and rate-limiting mechanisms is discussed with respect to the sensor response to NO.

\section{Experimental Section}

The NO sensors were composed of tape cast YSZ for the electrolyte and dense Au wire (0.25 mm diameter, Alfa Aesar) electrodes. The YSZ tape was prepared from YSZ powder (8 mol\% yttria-stabilized zirconia, Tosoh Corp.) that was ball milled with B-98 Butvar binder, phosphate ester for the dispersant, dipropylene glycol benzoate as the plasticizer, along with the solvents ethanol and xylene. The doctor blade method was used to cast this mixture into thin sheets, referred to as tapes. The YSZ tapes were used to construct two types of sensors with different electrode configurations. Sensors with electrode configuration 1 (EC1) had a Au wire electrode embedded between four layers of YSZ tape, and a second Au wire electrode that was wrapped around this arrangement. A slurry made 
from dissolving YSZ tape into ethanol was applied as a coating over the entire sensor assembly (see Figure 1). Sensors with electrode configuration 2 (EC2) were made by embedding two parallel Au wire electrodes between four layers of YSZ tape. Similarly, YSZ slurry was applied over the outer surfaces of the tapes to complete the sensors. Both types of sensors were fired at $1050{ }^{\circ} \mathrm{C}$ for $1 \mathrm{~h}$. Prior studies by the authors have found that this firing condition produces an electrolyte microstructure with a porosity of about $46 \%$ that promotes gas diffusion and electrochemical $\mathrm{NO}_{\mathrm{x}}$ sensing reactions [9]. After firing, the rectangular shaped $\mathrm{NO}_{\mathrm{x}}$ sensors were approximately $10 \mathrm{~mm} \times 5 \mathrm{~mm}$ with a thickness of about $1.5 \mathrm{~mm}$.

\section{Configuration EC1 Configuration EC2}

(a) Sensor diagram

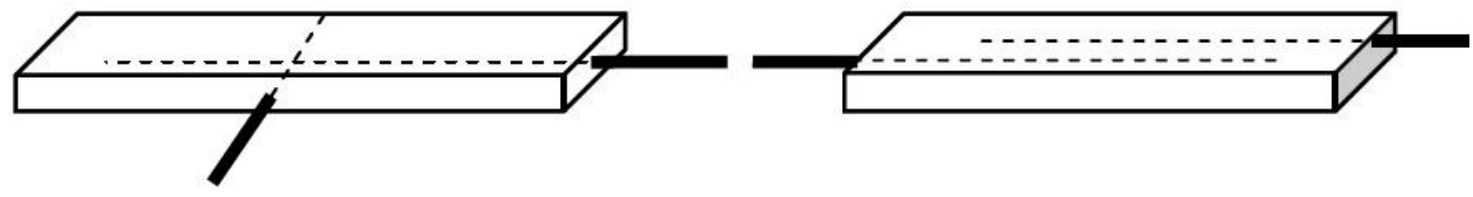

(b)
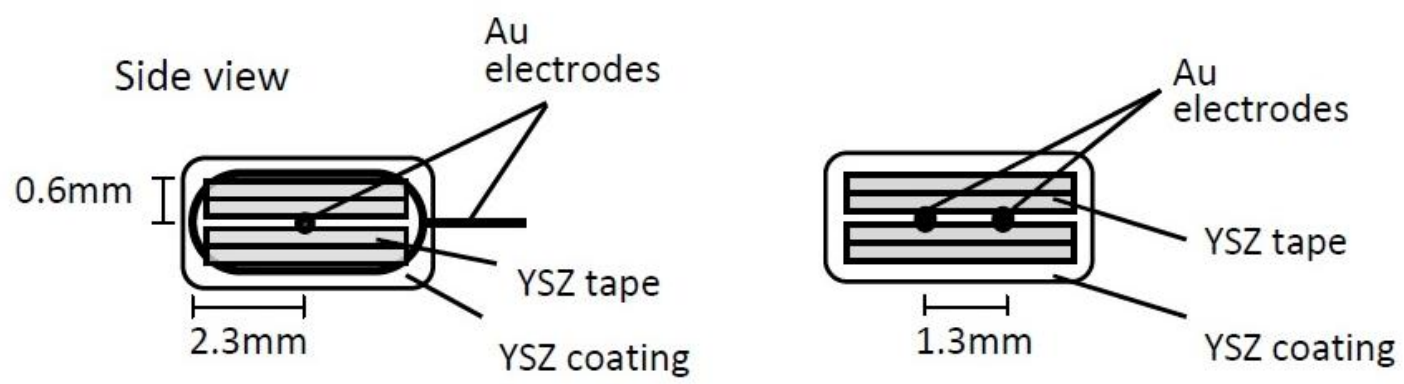

Figure 1. Diagrams of the NO sensors with electrode configurations (a) EC1 and EC2; (b) Cross sectional view illustrating the placement of the Au electrodes within the YSZ tape layers composing the sensor.

Impedance spectroscopy experiments were carried out using a Gamry Reference 600 in order to characterize the electrical response to NO for EC1 and EC2 sensor. The experiments were performed within a quartz tube that was placed in a furnace such that data could be collected for operating temperatures ranging from 600 to $700{ }^{\circ} \mathrm{C}$. The sensors were exposed to gas environments containing $1 \%-18 \% \mathrm{O}_{2}$ with $0-100 \mathrm{ppm} \mathrm{NO}$ where the total flow rate was $100 \mathrm{sccm}$. The gas composition was managed using thermo mass flow controllers that were connected to four certified gas cylinders (NO, $\mathrm{NO}_{2}, \mathrm{~N}_{2}$, and air) with $\mathrm{N}_{2}$ as the balance gas. Data were collected over a frequency range of $1 \mathrm{~Hz}$ to $1 \mathrm{MHz}$ with an excitation voltage of $50 \mathrm{mV}$. As this excitation voltage was within the linear voltage regime of the sensor equivalent circuit modeling could be performed with high accuracy to analyze the impedance results.

\section{Results and Discussion}

\subsection{Impedance Response}

Impedance measurements were carried out in order to determine the effect of electrode configuration on the electrical response of the $\mathrm{NO}_{\mathrm{x}}$ sensors. Figure 2 shows typical impedance data collected for $\mathrm{EC} 1$ 
and EC2 sensors at an operating temperature of $650{ }^{\circ} \mathrm{C}$ in the presence of $10.5 \% \mathrm{O}_{2}$ with and without $100 \mathrm{ppm}$ NO. The impedance response for $100 \mathrm{ppm} \mathrm{NO} 2$ was very similar to the response measured for $100 \mathrm{ppm}$ NO. Similar results were observed in previous studies [9]. Thermodynamic conversion of $\mathrm{NO}_{2}$ to $\mathrm{NO}$ causes the vast majority (over $90 \%$ ) of $\mathrm{NO}_{2}$ to convert to $\mathrm{NO}$ at temperatures over $600{ }^{\circ} \mathrm{C}$. Thus, data presented here concentrates on the NO response. The data was measured in triplicate for each testing condition to insure that stable, reproducible data was collected. The impedance data indicated two distinct arcs for both the EC1 and EC2 sensors. The incomplete high frequency arc (HFA) resulted from the frequency limit of the Gamry Reference 600. Bulk electrolyte properties associated with the porous YSZ microstructure, such as oxygen ion conductivity are described by the high frequency response. More importantly, the impedancemetric $\mathrm{NO}_{\mathrm{x}}$ sensor response is primarily described by electrode reactions, which are presented in the low frequency regime. The impedance response for EC1 sensors with the Au wire loop and embedded electrodes was substantially larger than the response of the EC2 sensors with parallel $\mathrm{Au}$ wire electrodes. In general, the impedance response of $\mathrm{NO}_{\mathrm{x}}$ sensors depends upon the material properties, molecular and electronic transport, as well as the following electrochemical reduction/oxidation reactions:

$$
\begin{gathered}
\frac{1}{2} \mathrm{O}_{2}+2 e^{-} \leftrightarrow O^{-2} \\
\mathrm{NO}_{2}+2 e^{-} \leftrightarrow \mathrm{NO}+\mathrm{O}^{-2}
\end{gathered}
$$

These reactions occur along the triple phase boundary (TPB) where the electrode, electrolyte and gas species come into contact with each another. The low frequency impedance response is influenced by TPB Reactions (1) and (2) [6,7]. Since the sensors are composed of the same materials, it is likely that similar reactions occurred at each sensor. However, the pathways associated with those reactions may have differed. The tortuous microstructure of the porous electrolyte and, in particular, the distance between the electrodes affects the molecular and ionic transport within the sensors. Figure 1 shows the distance between the wire loop and embedded electrodes in the EC1 sensors varied from approximately 0.6-2.3 mm; whereas, the parallel electrodes for EC2 sensors were about $1.3 \mathrm{~mm}$ apart. The variation in distance between the electrodes within $\mathrm{EC} 1$ sensors caused $\mathrm{NO}_{\mathrm{x}}$ and $\mathrm{O}_{2}$ gas species, as well as oxygen ions to travel longer distances through the tortuous pathways of the porous electrolyte in order to participate in TPB reactions. Similar observations have been made in solid oxide fuel cell (SOFC) studies where larger impedance measurements are reported for SOFCs composed of a thick film versus thin film electrolyte. [14,15] The thick film electrolyte results in a greater distance between the electrodes, thereby, creating a longer pathway for oxygen ion transport through the electrolyte. As a result greater ohmic losses occur, which contribute to higher impedance values. Thus, the longer pathways for gas and oxygen ion transport within the EC1 sensors most likely contributed to the larger impedance.

Equivalent circuit modeling with Gamry EIS300 software was used to simulate the impedance measurements and further analyze the electrical response of the sensors under various operating conditions. The equivalent circuit model that best fit the sensor impedance results was, $\left(\mathrm{R}_{1} \mathrm{CPE}_{1}\right)$ $\left(\mathrm{R}_{2} \mathrm{CPE}_{2}\right)$, as shown in Figure 2 for both sensor configurations. The resistor, $\mathrm{R}_{1}$, was associated with the HFA and interpreted as the ionic transport resistance of the porous YSZ electrolyte. Other studies have shown that the HFA dependents upon the porosity of the electrolyte as the tortuous pathways within the porous microstructure impede the flow of oxygen ions $[9,16]$. The low frequency arc (LFA) resistance, 
$\mathrm{R}_{2}$, described the interfacial resistance associated with TPB reactions. Such reactions include adsorption, dissociation, and diffusion of gases, as well as charge transfer, which can contribute to the electrode resistance. Further details on electrode reactions are discussed in follow sections. The equivalent circuit model accounted for the slight suppression of the arcs with constant phase elements, $\mathrm{CPE}_{1}$ and $\mathrm{CPE}_{2}$, which described the non-ideal capacitance behavior of the electrolyte and electrodes, respectively. Surface defects, interfacial reactions, as well as the morphology of the sensor components, can cause the time constant for various reactions to differ resulting in non-ideal capacitance behavior [6]. Table 1 shows the fitted values associated with the equivalent circuit model shown in Figure 2. The goodness of fit (i.e., Chi squared) describes the quality of the fit. The errors associated with the fitting parameters were $1 \%-4 \%$ and $5 \%-6 \%$ where the goodness of fit was on the order of $10^{-6}$ and $10^{-4}$, respectively. The impedance data collected under the various operating conditions were fit using the same model and had goodness of fit values within this range.

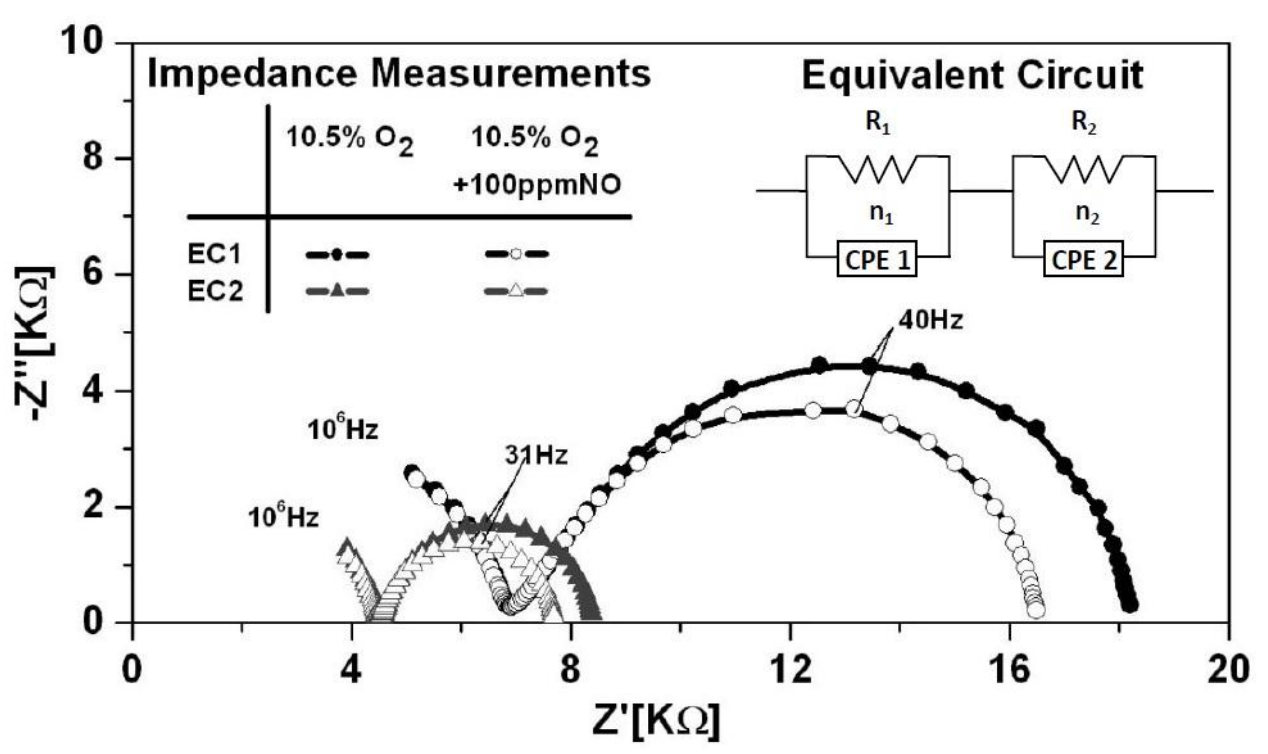

Figure 2. Typical Nyquist plot showing the impedance response of EC1 and EC2 sensors at an operating temperature of $650{ }^{\circ} \mathrm{C}$, in $10.5 \% \mathrm{O}_{2}$ with and without $\mathrm{NO}$ present. The equivalent circuit used to model the data is shown in the upper right corner of the plot. The model that fit the data is described by the solid lines.

Table 1. Equivalent circuit fitting parameters are shown for sensor impedance data collected at $650{ }^{\circ} \mathrm{C}$.

\begin{tabular}{|c|c|c|c|c|c|c|c|c|c|c|}
\hline \multirow{3}{*}{ Sensor } & \multirow{2}{*}{\multicolumn{3}{|c|}{$\begin{array}{c}\text { High Frequency Arc } \\
10.5 \% \mathrm{O}_{2}\end{array}$}} & \multicolumn{6}{|c|}{ Low Frequency Arc } & \multirow{3}{*}{ Goodness of Fit } \\
\hline & & & & \multicolumn{3}{|c|}{$10.5 \% 02$} & \multicolumn{3}{|c|}{$10.5 \% \mathrm{O}_{2}+100 \mathrm{ppm}$ NO } & \\
\hline & $\mathrm{CPE}_{1}(\mathrm{~F})$ & $\mathbf{n}_{1}$ & $R_{1}(\mathrm{k} \Omega)$ & $\mathrm{CPE}_{2}(\mathrm{~F})$ & $\mathbf{n}_{2}$ & $R_{2}(k \Omega)$ & $\mathrm{CPE}_{2}(\mathrm{~F})$ & $\mathbf{n}_{2}$ & $\mathbf{R}_{2}(\mathrm{k} \Omega)$ & \\
\hline EC1 & $1.11 \times 10^{-10}$ & 0.9 & 7.01 & $0.92 \times 10^{-6}$ & 0.8 & 11.65 & $0.89 \times 10^{-6}$ & 0.9 & 9.87 & $2.10 \times 10^{-4}$ \\
\hline $\mathrm{EC} 2$ & $0.75 \times 10^{-10}$ & 0.9 & 4.54 & $2.22 \times 10^{-6}$ & 0.9 & 3.90 & $2.24 \times 10^{-6}$ & 0.9 & 3.23 & $2.90 \times 10^{-6}$ \\
\hline
\end{tabular}

The fitted values for the CPE data generated for EC1 and EC2 sensors were used to calculate the capacitance, $\mathrm{C}$, associated with the high and low frequency sensor response according to the following equation: 


$$
C=\frac{[(R)(C P E)]^{\frac{1}{n}}}{R}
$$

where $\mathrm{R}$ was the resistance associated with the low frequency impedance arc, and $n$ describes the deviation from pure capacitance behavior. In the case where $n=1$, the constant phase element represents a pure capacitor. Figure 3 shows the capacitances, $\mathrm{C} 1$ and $\mathrm{C} 2$, with respect to NO concentration for the EC1 and EC2 sensors, respectively. The EC2 sensors had higher capacitance values in comparison to the EC1 sensors. Higher capacitance has been associated with increased oxygen coverage at the Au/YSZ interface [17]. If oxygen arrived at this interface faster than it could participate in TPB reactions, then the shorter path length between the embedded parallel electrodes in the EC2 sensors may have enabled oxygen accumulation at the Au/YSZ interface. As for the EC1 sensors, the greater distance between the wire loop and embedded electrodes may have caused oxygen transport to occur over a longer time period such that the rate of oxygen arriving at the Au/YSZ interface coincided more closely with TPB reaction rates. In such a case, oxygen arriving at the Au/YSZ interface would more immediately participated in interfacial reactions, such that limited accumulation occurred. This suggests that the rate of oxygen transport through the porous YSZ electrolyte in EC1 sensors agreed more closely with the rate of interfacial reactions. The data in Figure 3 also indicates that as the concentration of NO increased, the capacitance decreased, which suggests that oxygen coverage diminished as NO occupied more sites along the TPB.
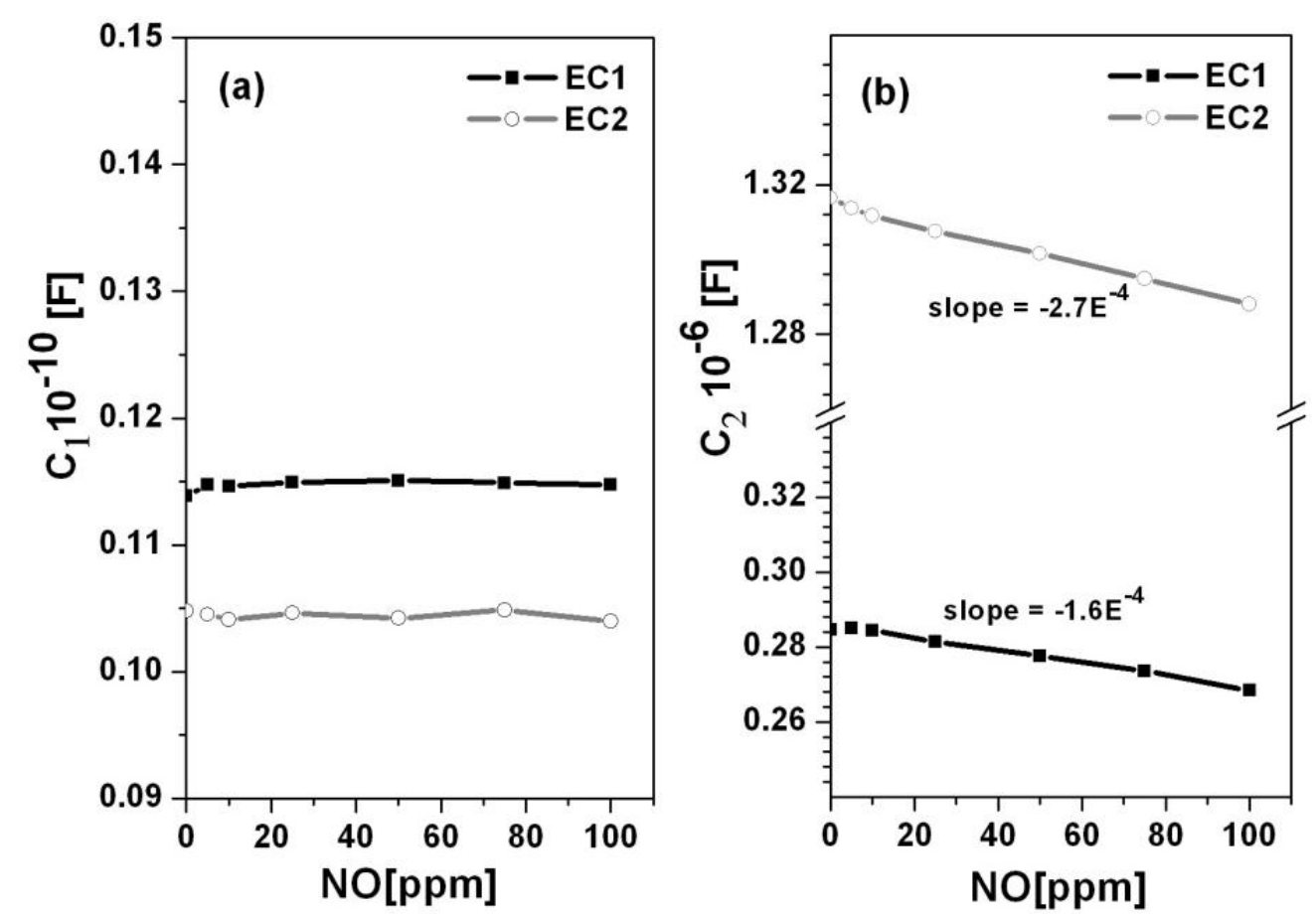

Figure 3. The capacitance versus NO concentration is shown for the (a) high and (b) low frequency arcs associated with the EC1 and EC2 sensors.

\subsection{NO Sensitivity}

Various methods have been used to assess NO sensor sensitivity. The operating conditions as well as material properties of the sensor components can significantly influence the degree of sensitivity 
observed by a given method. [18] Figure 4 shows NO sensitivity for EC1 and EC2 sensors in terms of the change in capacitance, $\Delta C / C$, where $\Delta C / C=\left[\left(C_{O 2}-C_{N O}\right) / C_{O 2}\right]$ [19]. The terms $C_{02}$ and $C_{N o}$ were the capacitance values calculated from fitted data for the LFAs according to Equation (3). Co2 was the baseline capacitance that was determined when only $10.5 \% \mathrm{O}_{2}$ was exposed to the sensor. The capacitance, $\mathrm{C}_{N O}$, was calculated based on the presence of a specific concentration of NO in the gas surrounding the sensor. The data in Figure 4, indicates the sensitivity to NO was significantly greater for EC1 versus EC2 sensors. These findings along with the capacitance data in Figure 3 suggest that lower oxygen coverage at the electrode/electrolyte interface in EC1 sensors may have allowed more NO reactions to take place at the TPB, which contributed to greater NO sensitivity.

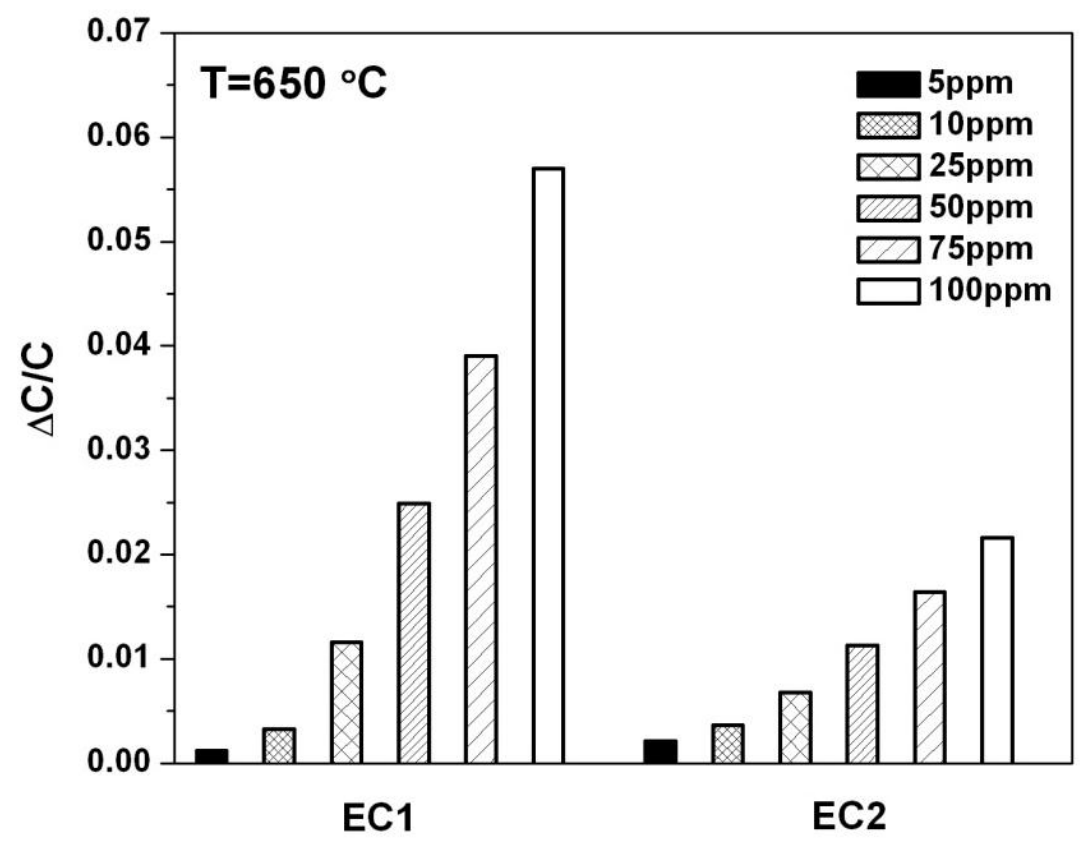

Figure 4. The change in capacitance is plotted for EC1 and EC2 sensors for NO concentrations ranging from 5 to $100 \mathrm{ppm}$.

The phase angle $\theta$, is a frequency dependent parameter that also can be used to evaluate the impedancemetric $\mathrm{NO}_{\mathrm{x}}$ sensor response. The relationship between the phase angle and the impedance is given by the equation $\theta=\tan ^{-1}\left(Z^{\prime \prime} / Z^{\prime}\right)$, where $Z^{\prime \prime}$ and $Z^{\prime}$ are the imaginary and real components of the impedance, respectively. NO sensitivity can be determined by calculating the percent change in the phase angle response, $\Delta \theta / \theta$, for a specific operating frequency when the sensor is exposed to NO. The percent change in phase is defined as $\Delta \theta / \theta=\left[\left(\theta_{O 2}-\theta_{N O}\right) / \theta_{O 2}\right]$, where $\theta_{O 2}$ represented the baseline phase when only $10.5 \% \mathrm{O}_{2}$ was present and $\theta_{N O}$ described the phase response for a specific concentration of NO. Figure 5 shows the NO sensitivity for EC1 and EC2 sensors based on the phase response at $40 \mathrm{~Hz}$. This data agrees with the sensitivity data presented in Figure 4, as EC1 sensors demonstrated greater NO sensitivity in comparison to EC2 sensors. Further comparison between Figures 4 and 5 indicates NO sensitivity based on $\Delta \theta / \theta$ is greater than the sensitivity associated with $\Delta C / C$, particularly for the EC2 sensors. The phase response data also shows a higher sensitivity at lower NO concentrations, specifically 5 and $10 \mathrm{ppm}$. It is important to note that NO sensitivity based on $\Delta \theta / \theta$ is dependent upon the sensor operating frequency. In general, the higher the operating frequency the more rapid the sensor response 
becomes to changes in NO concentration; however, NO sensitivity generally decreasing as the operating frequency increases. In this study, the $\Delta \theta / \theta$ data collected at $40 \mathrm{~Hz}$ was determined to be the most suitable operating frequency with respect to such tradeoffs.

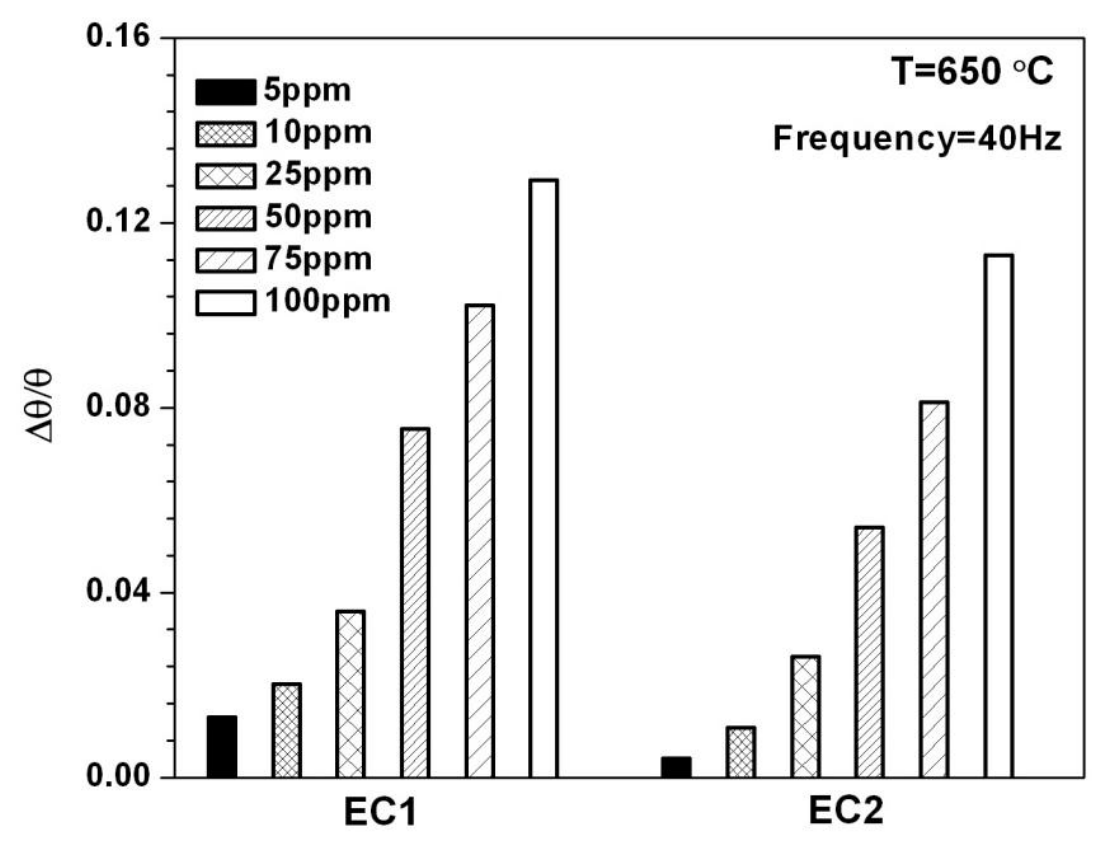

Figure 5. The change in the angular phase angle is plotted for EC1 and EC2 sensors for NO concentrations ranging from 5 to $100 \mathrm{ppm}$.

\subsection{Oxygen and Temperature Dependence}

The oxygen partial pressure and temperature dependence of the sensors can further understanding of potential rate limiting mechanisms and kinetic reactions that influence sensor behavior. The oxygen partial pressure dependence was determined for the low frequency arcs associated with the EC1 and EC2 sensors according to the power law relationship, $R \propto\left(\mathrm{pO}_{2}\right)^{m}$, where the slope, $\mathrm{m}$, describes the rate limiting step. As shown in Figure 6, a dependence of $R_{1} \propto\left(p O_{2}\right)^{-0.50}$ and $R_{2} \propto\left(p O_{2}\right)^{-0.62}$ was observed for EC1 and EC2 sensors, respectively. Studies concerning oxygen partial pressure dependence have reported that slope values corresponding to -0.5 indicate electrode surface reactions involving dissociative adsorption or atomic diffusion of oxygen as the rate limiting mechanism [20]. As the slope becomes closer to -1 gas diffusion has been considered as rate limiting [20]. The more negative slope dependence, $\mathrm{m}=-0.62$, for the EC2 sensors seems to suggest gas diffusion contributed to the rate limiting steps. It is possible that the diffusion depth to the electrode/electrolyte interface within the EC2 sensors limited gas diffusion. The EC2 sensors were composed of parallel electrodes that were embedded approximately $0.75 \mathrm{~mm}$ within in the electrolyte; whereas, the wire loop electrode around the EC1 sensors had a thin electrolyte coating of about $0.15 \mathrm{~mm}$ in thickness. Thus, $\mathrm{O}_{2}$ and NO gases traveled a shorter path to a TPB within the EC1 sensors, in comparison to EC2 sensors where the diffusion depth was greater. 


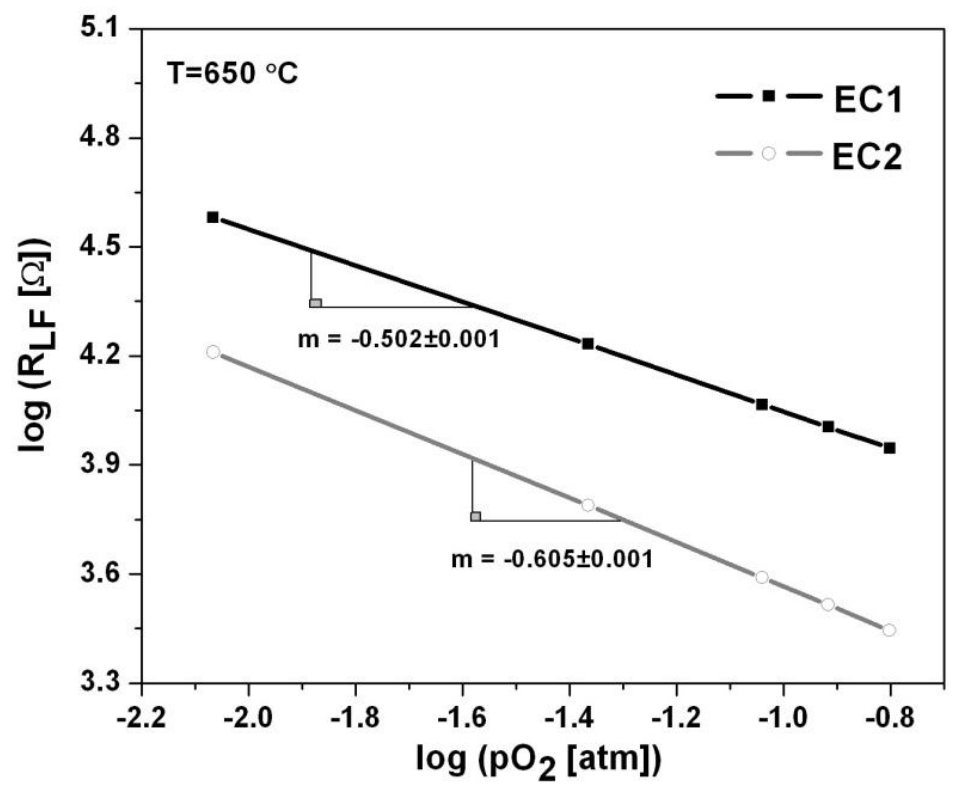

Figure 6. The oxygen partial pressure dependence of the EC1 and EC2 sensors is shown for data collected at $650{ }^{\circ} \mathrm{C}$ for oxygen concentrations ranging from $1 \%$ to $18 \%$.

Arrhenius plots shown in Figure 7 describe the temperature dependence of the sensors. The activation energies calculated from the slope of the Arrhenius plots were very similar for each electrode configuration as $\mathrm{Ea}_{1}=101.77 \pm 0.01 \mathrm{~kJ} / \mathrm{mol}$ and $\mathrm{Ea}_{2}=100.48 \pm 0.05 \mathrm{~kJ} / \mathrm{mol}$ for $\mathrm{EC} 1$ and $\mathrm{EC} 2$ sensors, respectively. The activation energy describes the temperature dependence of the electrode/electrolyte system. As the operating temperature increased the activation energy decreased suggesting that interfacial reactions were able to proceed more readily. The similar behavior described by the activation energy for the EC1 and EC2 sensors indicates a negligible relationship between the electrode configuration and temperature dependence of the sensors.

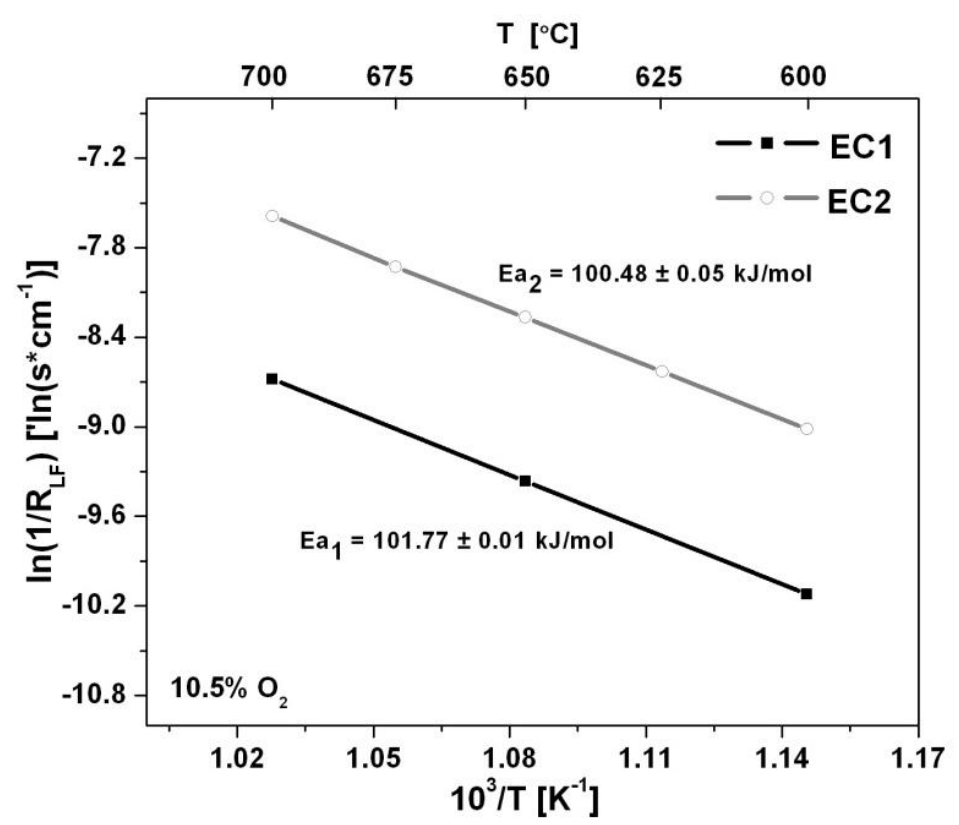

Figure 7. The temperature dependence is described by the Arrhenius plot for the EC1 and EC2 sensors along with corresponding activation energies. 


\section{Conclusions}

The effect of electrode configuration on NO sensitivity was investigated using Au/YSZ/Au sensors over an operating temperature range of $600-700{ }^{\circ} \mathrm{C}$. The electrode configuration seemed to primarily effect the transport distances for $\mathrm{NO}$ and $\mathrm{O}_{2}$ gas species and oxygen ions. The distance between the $\mathrm{Au}$ wire loop and embedded electrodes in the EC1 sensors resulted in longer pathways for gas and ionic transport between the electrodes, in comparison to the parallel electrodes within EC2 sensors. As a result the total impedance was larger for EC1 in comparison to EC2 sensors. The equivalent circuit model was the same for both sensor configurations; however, the fitted data results differed. In particular, the calculated capacitance values determined from the fitted data suggested that the oxygen coverage at the electrode/electrolyte interface was significantly lower for the wire loop electrode configuration of EC1 sensors. It is possible that the lower oxygen coverage allowed for higher NO coverage at the electrode/electrolyte interface, thereby, contributing to greater NO sensitivity for the EC1 sensors. Analysis of the oxygen partial pressure dependence suggested that dissociative adsorption or atomic diffusion were likely rate-limiting mechanisms for each sensor type. Although the electrolyte porosity was the same for both types of sensors, gas diffusion appeared to be an additional rate-limiting step for EC2 sensors as the gas diffusion path to TPBs was greater. The electrode configuration did not have a significant effect on temperature dependence of the sensors as the activation energies for the EC1 and EC2 sensors were similar.

\section{Acknowledgments}

The authors are grateful for the technical support provided by Robert Novak and Jaco Visser at Ford Motor Company; as well as the meaningful discussions with Leta Woo and Joe Fitzpatrick at EmiSense Technologies. The National Science Foundation provided funding for this work under the Louisiana EPSCoR Research Infrastructure Improvement LA-SiGMA grant (EPS-1003897).

\section{Author Contributions}

The scope of this study was defined by Erica P. Murray and Ling Cui. The experimental procedure and methods were determined by Erica P. Murray, and carried out by Ling Cui. Data analysis and interpretation, as well as the writing of the manuscript were a collaborative effort by both authors.

\section{Conflicts of Interest}

The authors declare no conflict of interest. 


\section{References}

1. Ross, Z.; English, P.B.; Scalf, R.; Gunier, R.; Smorodinsky, S.; Wall, S.; Jerrett, M. Nitrogen dioxide prediction in Southern California using land use regression modeling: Potential for environmental health analyses. J. Expo. Sci. Environ. Epidemiol. 2006, 16, 106-114.

2. Carlson, P.; Chen, E.; Kanseisen, K.; Nevers, C.; Pidgeon, B.; Pugliese, H.; Sohacki, L.; Vallion, T.; Wick, C.; Yang, C.-S. 2009-2011 Compliance Report: Vehicle and Engine Compliance Activities; EPA-420-R-13-006; United States Environmental Protection Agency: Washington, DC, USA, December 2013; pp. 1-74.

3. Mracek, D.; Kocl, P.; Marek, M.; Choi, J.-S.; Pihl, J.A.; Partridge, W.P. Dynamics of $\mathrm{N}_{2}$ and $\mathrm{N}_{2} \mathrm{O}$ peaks during and after the regeneration of lean NOx trap. Appl. Catal. B Environ. 2015, 166-167, 509-517.

4. Digiulio, C.D.; Pihl, J.A.; Choi, J.-S.; Parks II, J.E.; Lance, M.J.; Toops, T.J.; Amiridis, D. $\mathrm{N}_{3}$ formation over a lean NOx trap (LNT) system: Effects of lean/rich cycle timing and temperature. Appl. Catal. B Environ. 2014, 147, 698-710.

5. Plashnitsa, V.V.; Elumalai, P.; Fujio, Y.; Miura, N. Zirconia-based electrochemical gas sensors using nano-structured sensing materials aiming at detection of automotive exhausts. Electrochim. Acta 2009, 54, 6099-6106.

6. Martin, L.P.; Woo, L.Y.; Glass, R.S. Impedancemetric NOx sensing using YSZ electrolyte and $\mathrm{YSZ} / \mathrm{Cr}_{2} \mathrm{O}_{3}$ composite electrodes. J. Electrochem. Soc. 2007, 154, J97-J104.

7. Woo, L.Y.; Martin, L.P.; Glass, R.S.; Wang, W.; Jung, S.; Gorte, R.J.; Murray, E.P.; Novak, R.F.; Visser, J.H. Effort of electrode composition and microstructure on impedancemetric nitric oxide sensors based on YSZ electrolyte. J. Electrochem. Soc. 2008, 155, J32-J40.

8. West, D.L.; Montgomery, F.C.; Armstrong, T.R. Total NOx sensing elements with compositionally identical oxide electrodes. J. Electrochem. Soc. 2006, 153, H23-H28.

9. Cui, L.; Han, F.; Dai, W.; Murray, E.P. Influence of microstructure on the sensing behavior of NOx exhaust gas sensors. J. Electrochem. Soc. 2013, 161, B34-B38.

10. Kubersky, P.; Hamacek, A.; Nespurek, S.; Soukup, R.; Vik, R. Effect of the geometry of a working electrode on the behavior of a planar amperometric NO2 sensor based on solid polymer electrolyte. Sens. Actuators B Chem. 2013, 187, 546-552.

11. Ahmed, R.; Reifsnider, K. Study of influence of electrode geometry on impedance spectroscopy. Int. J. Electrochem. Sci. 2011, 6, 1159-1174.

12. White, B.; Chatterjee, S.; Macam, E.; Wachsman, E. Effect of electrode microstructure on the sensitivity and response time of potentiometric NOx sensors. J. Am. Ceram. Soc. 2008, 91, 2024-2031.

13. Macam, E.R.; White, B.M.; Blackburn, B.M.; Di Bartolomeo, E.; Traversa, E.; Wachsman, E.D. $\mathrm{La}_{2} \mathrm{CuO}_{4}$ sensing electrode configuration influence on sensitivity and selectivity for a multifunctional potentiometric gas sensor. Sens. Actuators B Chem. 2011, 160, 957-963.

14. Minh, N.Q. In Fourth International Symposium on Solid Oxide Fuel Cells, 2nd ed.; The Electrochemical Society Proceeding Series: Pennington, UK, 1995; pp. 138-139.

15. Tsai, T.; Perry, E.; Barnett, S. Low-temperature solid-oxide fuel cells utilizing thin bilayer electrolytes. J. Electrochem. Soc. 1997, 144, L130-L132. 
16. Steil, M.C.; Thevenot, F. Densification of Yttria-stabilized Zirconia impedance spectroscopy analysis. J. Electrochem. Soc. 1997, 144, 390-398.

17. Woo, L.Y.; Martin, P.L.; Glass, R.S.; Gorte, R.J. Impedance characterization of a model $\mathrm{AuYttria-Stabilized} \mathrm{zirconia/Au} \mathrm{electrochemical} \mathrm{cell} \mathrm{in} \mathrm{varying} \mathrm{oxygen} \mathrm{and} \mathrm{NOx} \mathrm{concentrations.}$ J. Electrochem. Soc. 2007, 154, J129-J135.

18. Fergus, J.W. Materials for high temperature electrochemical $\mathrm{NO}_{\mathrm{x}}$ gas sensors. Sens. Actuators $B$ Chem. 2007, 121, 652-663.

19. Cho, H.C.; Takase, S.; Song, J.H.; Shimizu, Y. Sensing behavior of solid-state impedancemetric NOx sensor using solid electrolyte transducer and oxide receptor. Sens. Actuators B Chem. 2013, 187, 94-98.

20. Mogni, L.; Grunbaum, N.; Prado, F.; Caneiro, A. Oxygen reduction reaction on ruddlesden-popper phases studied by impedance spectroscopy. J. Electrochem. Soc. 2011, 158, B202-B207.

(C) 2015 by the authors; licensee MDPI, Basel, Switzerland. This article is an open access article distributed under the terms and conditions of the Creative Commons Attribution license (http://creativecommons.org/licenses/by/4.0/). 